\title{
Coagulase-negative Staphylococcus species in bulk milk: Prevalence, distribution, and associated subgroup- and species-specific risk factors
}

\author{
A. De Visscher, ${ }^{* 1}$ S. Piepers, ${ }^{*}$ F. Haesebrouck, † K. Supré, $\ddagger$ and S. De Vliegher* \\ *M-team and Mastitis and Milk Quality Research Unit, Department of Reproduction, Obstetrics, and Herd Health, and \\ †Department of Pathology, Bacteriology, and Avian Diseases, Faculty of Veterinary Medicine, Ghent University, 9820 Merelbeke, Belgium \\ ‡Flanders Milk Control Centre, 2500 Lier, Belgium
}

\section{ABSTRACT}

Coagulase-negative staphylococci (CNS) have become the main pathogens causing bovine mastitis in recent years. A huge variation in species distribution among herds has been observed in several studies, emphasizing the need to identify subgroup- and speciesspecific herd-level factors to improve our understanding of the differences in ecological and epidemiological nature between species. The use of bulk milk samples enables the inclusion of a large(r) number of herds needed to identify herd-level risk factors and increases the likelihood of recovering enough isolates per species needed for conducting subgroup- and, eventually, species-specific analyses at the same time. This study aimed to describe the prevalence and distribution of CNS species in bulk milk samples and to identify associated subgroup- and species-specific herd-level factors. Ninety percent of all bulk milk samples yielded CNS. Staphylococcus equorum was the predominant species, followed by Staphylococcus haemolyticus and Staphylococcus epidermidis. A seasonal effect was observed for several CNS species. Bulk milk samples from herds with a loose-pack or a tiestall housing system were more likely to yield CNS species compared with herds with a freestall barn, except for S. epidermidis, Staphylococcus simulans, and Staphylococcus cohnii. In September, herds in which udders were clipped had lower odds of yielding Staphylococcus chromogenes, S. simulans, and Staphylococcus xylosus, the CNS species assumed to be most relevant for udder health, in their bulk milk than herds in which udder clipping was not practiced. Bulk milk of herds participating in a monthly veterinary udder health-monitoring program was more likely to yield these 3 CNS species. Herds always receiving their milk quality premium or predisinfecting teats before attachment of the milking cluster had lower odds of

Received May 17, 2016.

Accepted September 23, 2016.

${ }^{1}$ Corresponding author: Anneleen.Devisscher@UGent.be having $S$. equorum in their bulk milk. Herds not using a single dry cotton or paper towel for each cow during premilking udder preparation were more likely to have S. cohnii-positive bulk milk. Herds in which flushing with hot water or steam of the milking cluster after having milked a cow with a (sub)clinical mastitis was applied, were less likely to yield $S$. simulans, $S$. haemolyticus, and $S$. cohnii in their bulk milk. Always wearing gloves during milking decreased the odds of having Staphylococcus devriesei-positive bulk milk. Tap water from the public drinking system used as drinking water increased the odds of yielding S. simulans in the bulk milk. In conclusion, CNS are highly prevalent in bulk milk and might originate from the environment for some species (we hypothesize this is true for $S$. equorum or S. cohnii), or from within the udder (e.g., for S. simulans). Studies collecting bulk milk and quarter milk samples at the same time along with environmental samples are needed to determine the exact origin of the different (subgroups of) CNS species present in bulk milk using strain-typing techniques.

Key words: dairy cattle, risk factor, coagulasenegative staphylococci, herd

\section{INTRODUCTION}

Coagulase-negative staphylococci have become the main bovine subclinical mastitis pathogens in several regions and countries (Piepers et al., 2007; Reyher et al., 2011; Sztachańska et al., 2016). Research relying on genotypic identification demonstrated the abundant presence of diverse CNS species in different bovine habitats, such as the cows' environment (Piessens et al., 2011), milk samples (Santos et al., 2008; Park et al., 2011; Persson Waller et al., 2011), and udder-related habitats (Taponen et al., 2008; De Visscher et al., 2014, 2016a). Describing CNS prevalence and distribution in those habitats and identifying associated risk factors, as has been done for other mastitis pathogens, is the obvious next step toward a better understanding of the variation in epidemiological and ecological nature 
among species (Zadoks et al., 2001; Østerås et al., 2006; Fox, 2009). However, species-specific research requires extensive studies including a considerable number of herds, cows, and quarters to obtain enough isolates of each (subgroup of) species for further analyses (Vanderhaeghen et al., 2015) and to identify associated factors.

Bulk milk is a convenient matrix, as it is readily available as part of the (regulatory) milk quality screening programs in different countries and includes milk of all lactating animals in the herd whose milk is sold (and not discarded). Bulk milk has already shown its value for the identification of herd-level management practices associated with the presence of Staphylococcus aureus (Olde Riekerink et al., 2010). Using bulk milk rather than composite or quarter milk samples conveniently enables the inclusion of a large(r) number of herds needed specifically to study herd-level risk factors. Bulk milk has actually been used for detecting genes encoding CNS virulence factors (Bertelloni et al., 2015) and for evaluating the suitability of mannitol salt agar for CNS recovery (De Visscher et al., 2013). The current study aimed (1) to describe the herd-level prevalence and distribution of CNS species in Flemish dairy herds using bulk milk samples, (2) to assess the variation in the presence of (subgroups of) different CNS species among herds, and (3) to identify associated herd-level risk factors.

\section{MATERIALS AND METHODS}

\section{Herds, Samples, and Data}

In the provinces of Antwerp, Flemish Brabant, Limburg, East Flanders, and West Flanders, 19, 5, 11, 28 , and 37 herds $(\mathrm{n}=100)$ were randomly selected from the database of the Flanders Milk Control Center (MCC Flanders, Lier, Belgium) using the RAND function (Excel 2010, Microsoft Corp., Redmond, WA) matching the relative distribution of dairy herds per province in Flanders. The selected herds had an average milk quota of 449,000 $\mathrm{kg} / \mathrm{yr}$, ranging between 92,000 and 1,500,000 kg. A herringbone milking parlor was the most commonly found milking parlor setup (n $=52)$, followed by a tiestall $(\mathrm{n}=20)$, a tandem parlor $(\mathrm{n}=18)$, a side-by-side parlor $(\mathrm{n}=6)$, an automated milking system $(\mathrm{n}=2)$, and a rotary parlor $(\mathrm{n}=1)$. In one herd, a herringbone milking parlor was replaced by an automated milking system during the year of sampling (i.e., 2013). Fifty herds only housed dairy cattle, whereas the other half also farmed pigs, beef cattle, or poultry.

Bulk milk samples were collected 3 times per herd with a 3-mo interval in 2013 (March, June, and September) as part of the mandatory milk quality screen- ing program executed by MCC and used for this study. Bulk milk-quality data were retrieved from MCC. The geometric mean bulk milk SCC in the month of sampling (March, June, and September) was calculated based on 4 weekly records and revealed a minimum, a maximum, and an arithmetic average of 74,000 , 539,000 , and 235,000 cells/mL, respectively. Several herd-level factors potentially associated with the presence of (subgroups of) CNS species in bulk milk were collected through a questionnaire and covered the entire study period (i.e., January-December 2013; Table 1).

\section{Laboratory Analyses}

Bulk milk samples $(n=300)$ were collected at the dairy farm and plated on mannitol salt agar (MSA; Oxoid, Erembodegem, Aalst, Belgium; 1 bulk milk sample per plate) in the laboratory of MCC Flanders (De Visscher et al., 2013). After an aerobic incubation of $24 \mathrm{~h}$, plates were transported at $4^{\circ} \mathrm{C}$ to the Mastitis and Milk Quality Research Lab (Faculty of Veterinary Medicine, Ghent University, Merelbeke, Belgium). All phenotypically different colony types were counted, picked up (1 colony per colony type), and subcultured on esculin blood agar (Oxoid) to obtain pure cultures. Afterward, plates were aerobically incubated $\left(37^{\circ} \mathrm{C}\right)$ for another $24 \mathrm{~h}$ and again examined. All recovered isolates suspected of belonging to the group of CNS were stored at $-80^{\circ} \mathrm{C}$ or immediately subjected to species identification using transfer RNA intergenic spacer PCR (tDNA-PCR). If no identification could be obtained with this technique, 16S rRNA gene sequencing was used (Supré et al., 2009).

\section{CNS Species Distribution}

The CNS species distribution in all bulk milk samples $(\mathrm{n}=300)$ in 100 Flemish dairy herds at the 3 sampling occasions (i.e., March, June, and September 2013) was computed (Table 2).

\section{Questionnaire Data and Statistical Analysis}

Before any statistical analysis was performed, observations were checked for unlikely or missing values. Complete questionnaire data were available from 95 herds.

Multilevel logistic regression models were fit applying reweighted iterative generalized least squares and first-order penalized quasi-likelihood in MLwiN 2.16 (Centre for Multilevel Modeling, University of Bristol, Bristol, UK). Month of sampling (March, June, and September) was forced into all models as a fixed effect and herd was added as a random effect to account for 


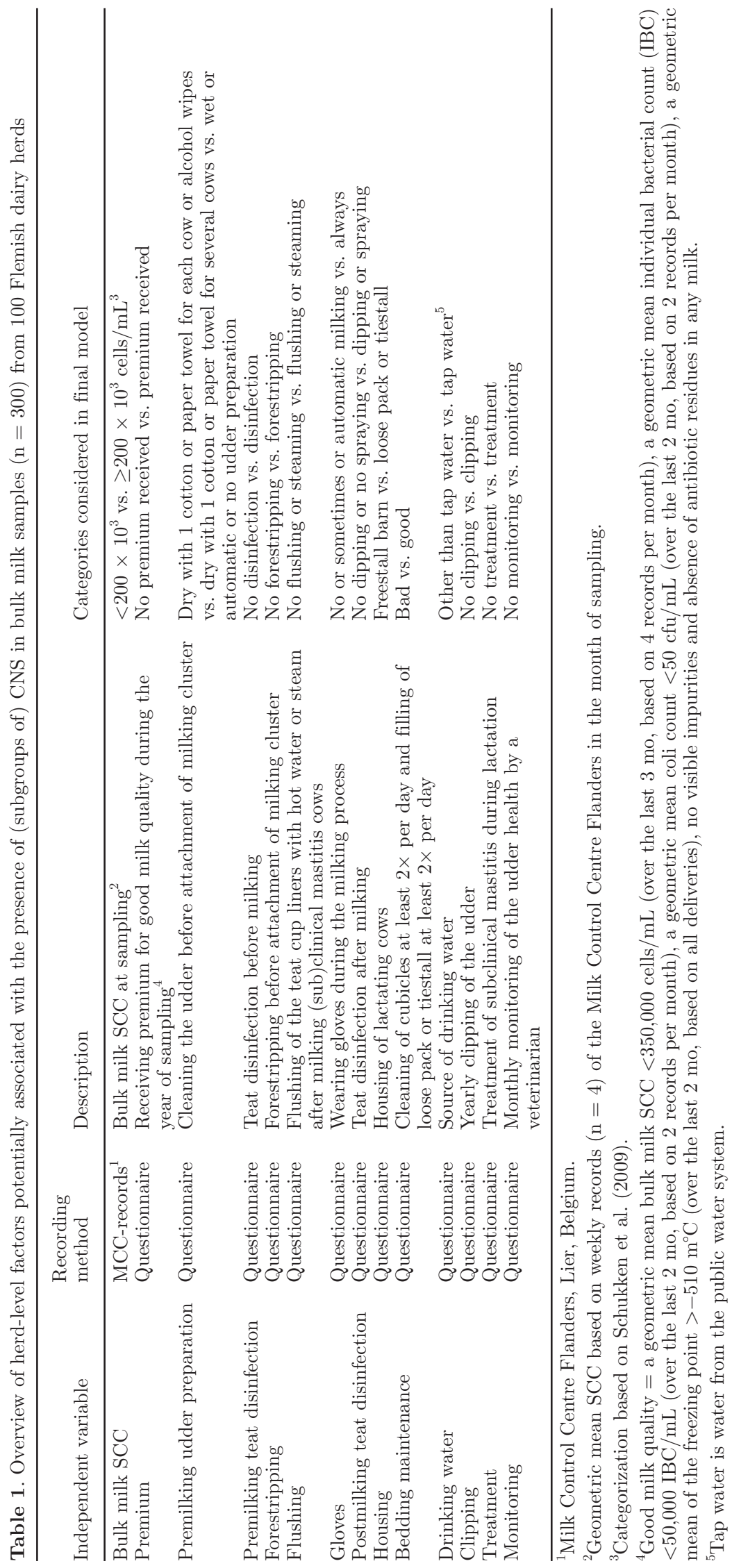


clustering of observations (3 samplings) within herds. Several binary outcome variables were created according to the effect on udder health (1) and the origin and ecological nature of the species $(2,3)$ : the presence of (1) the more relevant CNS for udder health (Staphylococcus chromogenes, Staphylococcus simulans, and Staphylococcus xylosus; Supré et al., 2011; Fry et al., 2014; De Visscher et al., 2015) in a bulk milk sample versus CNS-negative bulk milk or bulk milk with (an) other CNS species, (2) the so-called host-adapted CNS species (S. chromogenes and Staphylococcus epidermidis; Vanderhaeghen et al., 2015) versus CNS-negative bulk milk, and (3) the so-called environmental CNS species (Staphylococcus cohnii, Staphylococcus equorum, Staphylococcus saprophyticus, and Staphylococcus sciuri; Piessens et al., 2011) versus CNS-negative bulk milk. Second, species-specific risk factors were identified for all Staphylococcus species of which more than 25 isolates were available (presence of such species versus CNS-negative bulk milk); that is, S. epidermidis, S. chromogenes, S. simulans, S. xylosus, Staphylococcus haemolyticus, Staphylococcus devriesei, S. cohnii, S. equorum, and S. sciuri, as well as for Staphylococcus aureus (presence of $S$. aureus versus culture-negative bulk milk).

The proportion of variation for the different outcome variables at the herd and observation level was estimated for the null models using variance components analysis (MLWiN 2.16). The variance at the lowest (observation) level was assumed $\pi^{2} / 3$, as described by Goldstein et al. (2002).

Univariable models of all above-mentioned outcome variables $(\mathrm{n}=13)$ and the independent factors (Table 1) were fit. Statistical significance in this first step was assessed at $P<0.15$. Subsequently, Spearman rank correlation coefficients were calculated among all significant independent variables, with a margin of $|0.6|$, to identify multicollinearity in the next steps. Finally, multivariable models were fit using backward stepwise elimination and assessing statistical significance at $P<$ 0.05. Biologically relevant interaction terms among the remaining statistically significant independent factors were tested and kept in the final models if significant $(P<0.05)$. A factor was considered a confounder if its

Table 2. Coagulase-negative Staphylococcus species distribution in bulk milk samples $(\mathrm{n}=300)$ from 100 Flemish dairy herds at 3 sampling occasions (March, June, September)

\begin{tabular}{|c|c|c|c|c|c|c|c|c|}
\hline \multirow[b]{2}{*}{ Species } & \multicolumn{2}{|c|}{ March } & \multicolumn{2}{|c|}{ June } & \multicolumn{2}{|c|}{ September } & \multicolumn{2}{|c|}{ Total } \\
\hline & No. ${ }^{1}$ & $\%^{2}$ & No. & $\%$ & No. & $\%$ & No. & $\%$ \\
\hline Staphylococcus equorum ${ }^{3}$ & 47 & 33.6 & 47 & 24.1 & 44 & 18.6 & 138 & 24.1 \\
\hline Staphylococcus haemolyticus & 18 & 12.9 & 25 & 12.8 & 31 & 13.1 & 74 & 12.9 \\
\hline Staphylococcus epidermidis ${ }^{4}$ & 13 & 9.3 & 14 & 7.2 & 16 & 6.8 & 43 & 7.5 \\
\hline Staphylococcus simulans 5 & 3 & 2.1 & 5 & 2.6 & 30 & 12.7 & 38 & 6.6 \\
\hline Staphylococcus cohnii ${ }^{3}$ & 7 & 5.0 & 15 & 7.7 & 13 & 5.5 & 35 & 6.1 \\
\hline Staphylococcus sciuri ${ }^{3}$ & 8 & 5.7 & 8 & 4.1 & 18 & 7.6 & 34 & 5.9 \\
\hline Staphylococcus xylosus ${ }^{5}$ & 7 & 5.0 & 14 & 7.2 & 12 & 5.1 & 33 & 5.8 \\
\hline Staphylococcus chromogenes ${ }^{4,5}$ & 11 & 7.9 & 9 & 4.6 & 12 & 5.1 & 32 & 5.6 \\
\hline Staphylococcus saprophyticus ${ }^{3}$ & 0 & 0.0 & 14 & 7.2 & 14 & 5.9 & 28 & 4.9 \\
\hline Staphylococcus devriesei & 2 & 1.4 & 11 & 5.6 & 13 & 5.5 & 26 & 4.5 \\
\hline Staphylococcus fleurettii & 7 & 5.0 & 6 & 3.1 & 4 & 1.7 & 17 & 3.0 \\
\hline Staphylococcus warneri & 4 & 2.9 & 4 & 2.1 & 6 & 2.5 & 14 & 2.4 \\
\hline Staphylococcus hominis & 5 & 3.6 & 4 & 2.1 & 4 & 1.7 & 13 & 2.3 \\
\hline Staphylococcus caseolyticus & 1 & 0.7 & 5 & 2.6 & 5 & 2.1 & 11 & 1.9 \\
\hline Staphylococcus succinus & 1 & 0.7 & 5 & 2.6 & 2 & 0.8 & 8 & 1.4 \\
\hline Staphylococcus vitulinus & 4 & 2.9 & 3 & 1.5 & 0 & 0.0 & 7 & 1.2 \\
\hline Staphylococcus arlettae & 0 & 0.0 & 2 & 1.0 & 3 & 1.3 & 5 & 0.9 \\
\hline Staphylococcus auricularis & 1 & 0.7 & 1 & 0.5 & 3 & 1.3 & 5 & 0.9 \\
\hline Staphylococcus agnetis & 0 & 0.0 & 0 & 0.0 & 3 & 1.3 & 3 & 0.5 \\
\hline Staphylococcus gallinarum & 0 & 0.0 & 1 & 0.5 & 1 & 0.4 & 2 & 0.3 \\
\hline Staphylococcus pasteuri & 0 & 0.0 & 1 & 0.5 & 1 & 0.4 & 2 & 0.3 \\
\hline Staphylococcus hyicus & 1 & 0.7 & 0 & 0.0 & 0 & 0.0 & 1 & 0.2 \\
\hline Staphylococcus lentus & 0 & 0.0 & 1 & 0.5 & 0 & 0.0 & 1 & 0.2 \\
\hline Staphylococcus rostri & 0 & 0.0 & 0 & 0.0 & 1 & 0.4 & 1 & 0.2 \\
\hline Staphylococcus nepalensis & 0 & 0.0 & 0 & 0.0 & 1 & 0.4 & 1 & 0.2 \\
\hline Total & 140 & 100 & 195 & 100 & 237 & 100 & 572 & 100 \\
\hline
\end{tabular}

${ }^{1}$ Number of herds $(\mathrm{n}=100)$ yielding a certain CNS species in bulk milk.

${ }^{2}$ Percentage of CNS species within month of sampling.

${ }^{3}$ Staphylococcus equorum, S. cohnii, S. sciuri, and S. saprophyticus are considered environmental species.

${ }^{4}$ Staphylococcus epidermidis and S. chromogenes are considered host-adapted species.

${ }^{5}$ Staphylococcus simulans, S. xylosus, and S. chromogenes represent the CNS species being more relevant for udder health. 
removal caused a relative change $>25 \%$ in the regression coefficients of the remaining variables or with a regression coefficient between -0.4 and 0.4 if an absolute change $>0.1$ was observed (Noordhuizen et al., 2001). To correct for multiple comparisons, a Bonferroni correction was applied. To test the goodness-of-fit of all models, the observation-level standardized residuals were plotted against the observation-level predicted values, all revealing good models. Odds ratios (OR) with $95 \%$ confidence intervals were reported.

The relation between the presence of the more relevant CNS species (i.e., S. chromogenes, S. simulans, and S. xylosus; Supré et al., 2011; Fry et al., 2014; De Visscher et al., 2015; outcome variable), and the presence of the major pathogen, S. aureus, in bulk milk (independent variable) was determined using a logistic mixed regression model with month of sampling forced in the model as fixed effect and herd included as random effect as described above. Significance was assessed at $P<0.05$.

\section{RESULTS}

\section{CNS Species Distribution}

All except 1 of the collected bulk milk samples $(\mathrm{n}=$ 299) yielded growth on MSA, with a range of 1 to 9 phenotypically different colony types. Several isolates with different colony types belonged to the same CNS species or to other genera after tDNA-PCR or $16 \mathrm{~S}$ rRNA gene sequencing, generating 572 CNS isolates available for further analysis. Ninety percent $(\mathrm{n}=271)$ of all bulk milk samples were CNS-positive with 1 to 6 different CNS species per sample. In total, 25 different CNS species were identified (Table 2).

Ninety-two out of 300 bulk milk samples (31\%) collected from 62 herds harbored at least 1 of the CNS species that are more relevant for udder health (i.e., S. chromogenes, S. simulans, and S. xylosus). The host-adapted CNS species (S. chromogenes and S. epidermidis) were isolated from 70 out of 300 bulk milk samples (23\%) from 48 herds, whereas the environmental species (S. cohnii, S. equorum, S. saprophyticus, and S. sciuri) were collected from 201 out of 300 bulk milk samples (67\%) from 95 herds. The species distribution is shown in Table 2. Eighty-nine bulk milk samples (30\%) collected from 61 out of the 100 herds were $S$. aureus-positive (45 in March, 21 in June, and 23 in September). The number of herds yielding a certain CNS species in March, June, or September is shown in Figure 1. Staphylococcus equorum, S. haemolyticus, S. epidermidis, S. sciuri, S. cohnii, S. xylosus, and $S$. devriesei, as well as $S$. aureus, were isolated from the same herd(s) on all 3 sampling occasions.
Bacteria other than staphylococci were either phenotypically or genotypically (i.e., using tDNA-PCR or 16S rRNA gene sequencing) identified as esculinpositive streptococci $(\mathrm{n}=156)$, Bacillus spp. $(\mathrm{n}=116)$, Acinetobacter spp. $(\mathrm{n}=33)$, Corynebacterium spp. (n $=28)$, Pseudomonas $(\mathrm{n}=26)$, Alcaligenaceae $(\mathrm{n}=14)$, Psychrobacter spp. $(\mathrm{n}=12)$, Jeotgalicoccus spp. ( $\mathrm{n}=$ $11)$, and other gram-negative bacteria $(\mathrm{n}=2)$. Also, fungi $(\mathrm{n}=3)$ and yeasts $(\mathrm{n}=3)$ were identified.

\section{Statistical Analyses}

Variance Components. In all null models, most of the variation in the outcome variables resided at the observation level (Table 3; Supplemental Table S1, https://doi.org/10.3168/jds.2016-11476). However, the herd-level variation was highest for the subgroup of the host-adapted CNS (34\%). For the subgroup of environmental CNS and for S. aureus, 24 and $13 \%$ of the variation, respectively, was observed at the herd level. The herd-level variance for the specific CNS species ranged from 26 to $36 \%$.

Univariable Analyses. Univariable analyses revealed 4 factors that were significantly associated with the presence of different subgroups of CNS species in each model (Supplemental Table S2, https:// doi.org/10.3168/jds.2016-11476). The species-specific univariable analyses showed 5 herd-level factors to be significantly associated with the presence in bulk milk of $S$. haemolyticus, S. devriesei, or S. equorum, 4 factors for the presence of $S$. epidermidis, $S$. xylosus, or $S$. sciuri, and 3 factors for the presence of $S$. chromogenes, $S$. simulans, or S. cohnii (Supplemental Table S3, https:// doi.org/10.3168/jds.2016-11476). Univariable models for $S$. saprophyticus $(\mathrm{n}=28)$ did not converge due to low numbers, as was also observed for some analyses with $S$. aureus as the outcome variable. Staphylococcus aureus was only significantly associated with 1 independent variable (i.e., flushing, $P=0.07$; Supplemental Table S3). Overall, significant associations were not identified with bulk milk SCC, fore stripping, or with postmilking teat disinfection. Strong correlations between 2 or more factors or confounding were not observed.

Multivariable Subgroup-Specific Risk Factors Analyses. Table 4 presents the different final multilevel, multivariable logistic regression models for the subgroups of CNS species. The more relevant CNS species (i.e., S. chromogenes, S. simulans, and S. xylosus) as well as the environmental CNS species (i.e., $S$. cohnii, S. equorum, S. saprophyticus, and S. sciuri) were significantly more often observed in bulk milk collected in June (i.e., the outdoor season for most herds) and September (i.e., the end of the outdoor season for most herds) as opposed to March (i.e., the end of the indoor 
Table 3. Variance components at the herd and observation level of the null models for the presence of subgroups ${ }^{1}$ of CNS species in bulk milk samples $(\mathrm{n}=300)$

\begin{tabular}{|c|c|c|c|c|c|c|c|c|c|}
\hline Level & \multicolumn{3}{|c|}{ More relevant CNS species ${ }^{1}$} & \multicolumn{3}{|c|}{ Host-adapted CNS species ${ }^{1}$} & \multicolumn{3}{|c|}{ Environmental CNS species ${ }^{1}$} \\
\hline Observation & 3.29 & - & 90.24 & 3.29 & - & 66.37 & 3.29 & - & 75.61 \\
\hline Total variance & 3.65 & & 100 & 4.96 & & 100 & 4.35 & & 100 \\
\hline
\end{tabular}

${ }^{1}$ Staphylococcus chromogenes, Staphylococcus simulans, and Staphylococcus xylosus represent the CNS species being more relevant for udder health; S. chromogenes and Staphylococcus epidermidis are considered host-adapted species; and Staphylococcus cohnii, Staphylococcus equorum, Staphylococcus saprophyticus, and Staphylococcus sciuri are considered environmental species.

${ }^{2}$ Variance components.

season for most herds). Host-adapted CNS, S. chromogenes and S. epidermidis, were cultured in the same quantity from the bulk milk samples collected in March, June, and September. Herds with lactating cows and heifers housed in either a loose pack or a tiestall had higher odds of yielding each of the 3 CNS subgroups in bulk milk, with an OR of $2.5(95 \% \mathrm{CI}=1.4-4.8)$ for the more relevant CNS species, 13.1 (95\% CI $=1.4-123.8)$ for the host-adapted CNS species, and 11.4 (95\% CI $=1.4-90.8)$ for the environmental CNS species. In Sep- tember, herds in which udders were clipped annually had lower odds of yielding the CNS species previously reported to be associated with an elevated quarter SCC in their bulk milk than herds in which the udders were not clipped annually (Figure 2). Herds participating in a monthly veterinary udder health-monitoring program were more likely to yield the more relevant CNS species in their bulk milk samples.

Multivariable Species-Specific Risk Factor Analyses. Tables 5, 6, and 7 show the different final

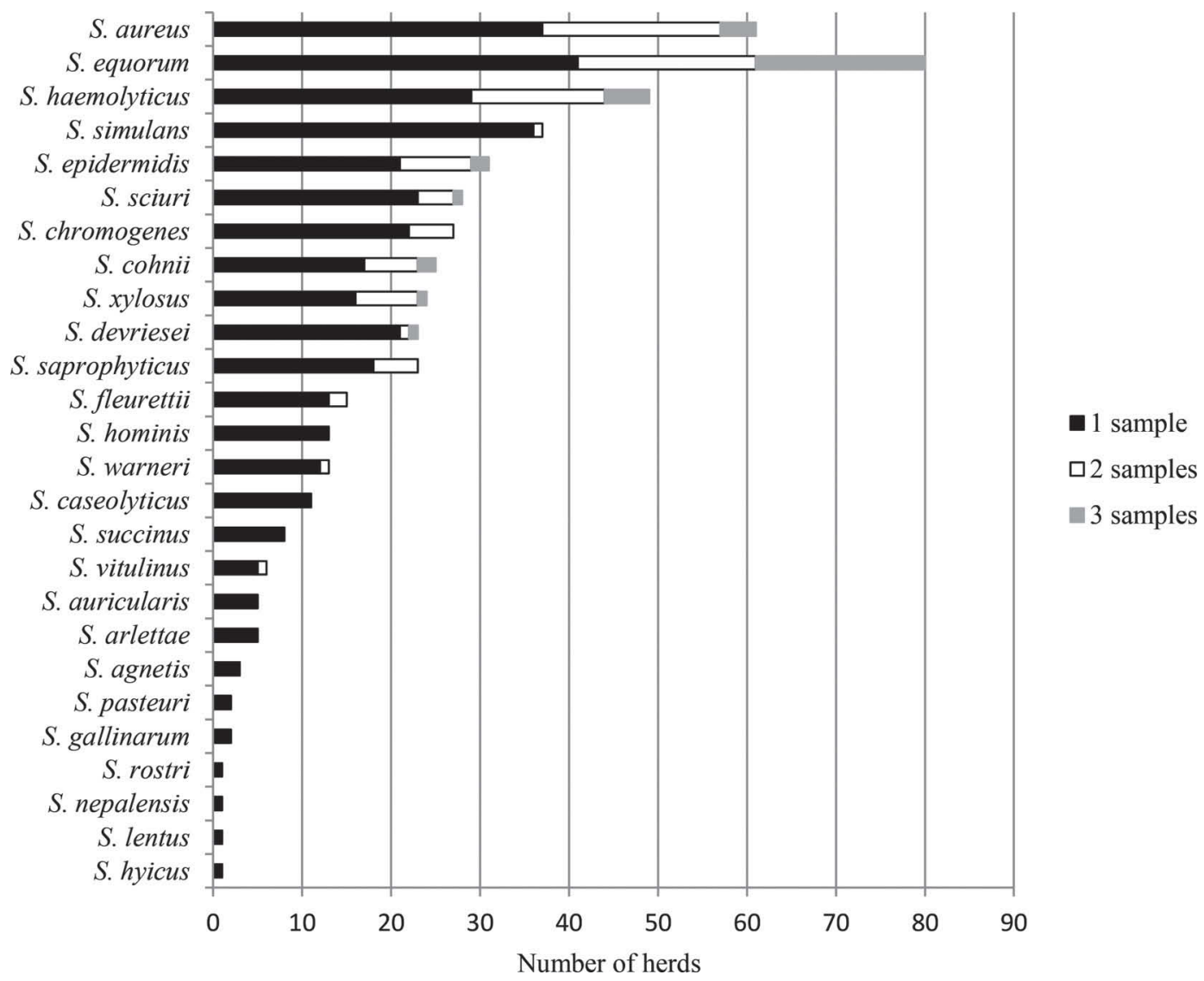

Figure 1. Number of herds $(\mathrm{n}=100)$ yielding a certain CNS species or Staphylococcus aureus in bulk milk in 1, 2, or 3 out of the 3 samplings (March, June, and September). 


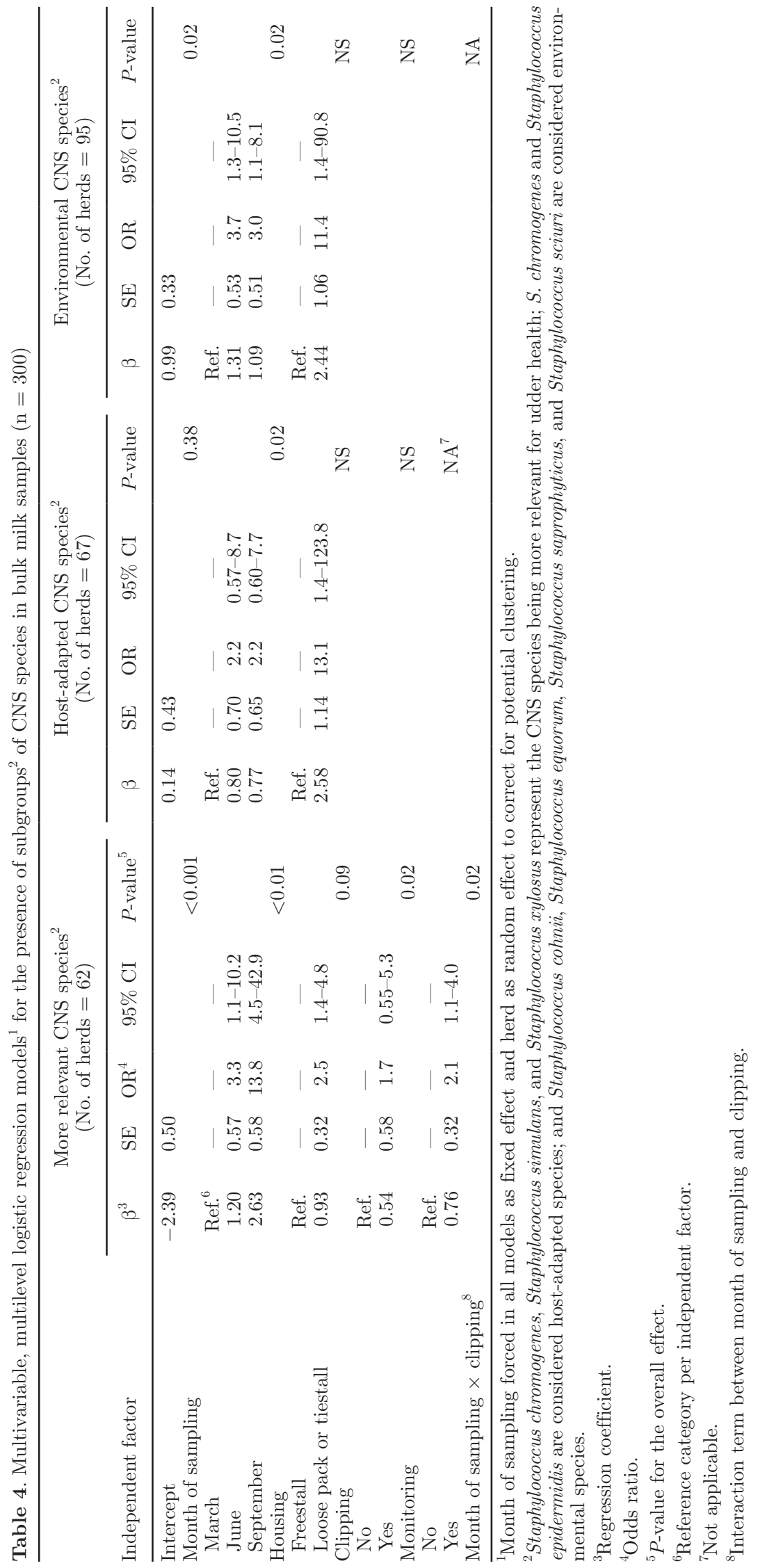


multilevel, multivariable logistic regression models for individual CNS species. None of the evaluated herd-level factors was significantly associated with the presence of S. epidermidis in bulk milk. Staphylococcus cohnii was significantly more often observed in bulk milk collected in June and September as opposed to March. A seasonal effect was also seen for $S$. simulans, $S$. devriesei, and $S$. sciuri, as they were all more frequently recovered from bulk milk collected in September as opposed to March. For the 3 latter species, no difference was observed among bulk milk samples collected in June and March. Staphylococcus epidermidis, S. chromogenes, and $S$. equorum were equally present in the samples collected in March, June, and September. Housing cows in a loose pack stall and a tiestall increased the odds of yielding $S$. chromogenes, $S$. xylosus, $S$. haemolyticus, $S$. devriesei, $S$. equorum, and $S$ sciuri. Herds in which the milking cluster was not flushed with hot water or steam after having milked a cow with (sub)clinical mastitis were more likely to have $S$. simulans-, S. haemolyticus-, and $S$. cohnii-positive bulk milk. Herds drinking tap water had higher odds of yielding $S$. simulans in their bulk milk. Not or only sometimes wearing gloves during milking increased the odds of having $S$. devriesei in the bulk milk. Herds always receiving their milk quality premium were less likely to yield $S$. equorum in their bulk milk. Teat disinfection before attachment of the milking cluster decreased the odds of yielding $S$. equorum in the bulk milk. Herds using a dry cotton or paper towel for several cows during the premilking udder preparation were more likely to have S. cohniipositive bulk milk opposed to those that used a single dry cotton or paper towel for each cow.

Association of Staphylococcus aureus and More Relevant $\boldsymbol{C N S}$. Herds with bulk milk positive

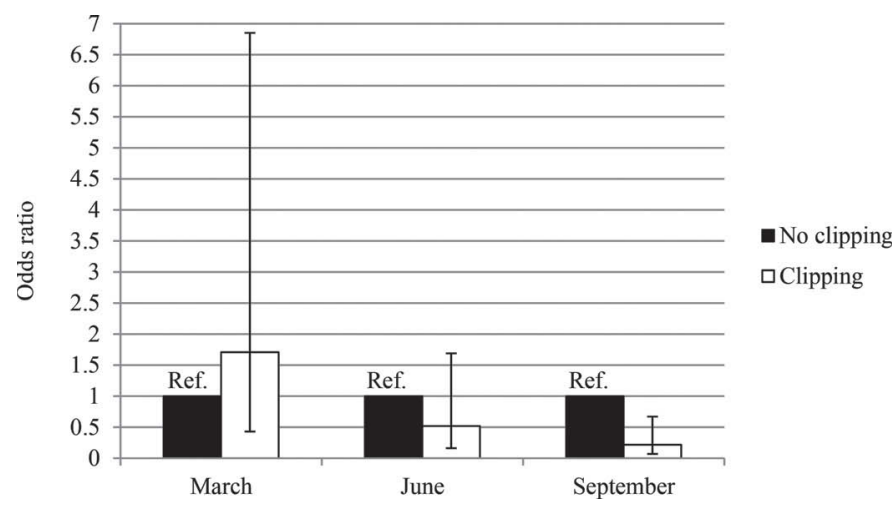

Figure 2. Interaction term between clipping (no clipping vs. clipping) and month of sampling (March, June, and September) visualized using odds ratios with $95 \%$ CI for the presence of the for udder health more relevant CNS species (i.e., Staphylococcus chromogenes, Staphylococcus simulans, and Staphylococcus xylosus) in bulk milk samples $(\mathrm{n}=300)$ from 100 Flemish dairy herds (as shown in Table 4). for $S$. aureus had lower odds of having CNS species being associated with elevated qSCC (i.e., S. chromogenes, S. simulans, and $S$. xylosus) in their bulk milk $(\mathrm{OR}=0.4 ; 95 \% \mathrm{CI}=0.2-0.8$; Supré et al., 2011; Fry et al., 2014; De Visscher et al., 2015).

Post-Hoc Power Calculation. A post-hoc power calculation was conducted. Twenty-six bulk milk samples $(\mathrm{n}=300)$ were positive for $S$. devriesei, whereas the so-called environmental species were isolated from 201 bulk milk samples. With 26 positive samples and 29 negative bulk milk samples (the model concerning $S$. devriesei), an association corresponding to an OR of 3.0 $(\alpha=0.05$ ), assuming 50 and $80 \%$ exposure among the negative bulk milk samples, was detected with 47.6 and $24.9 \%$ power, respectively. With 201 positive samples and 29 negative bulk milk samples (the model concerning the so-called environmental species), an association corresponding to an OR of $3.0(\alpha=0.05)$, assuming 50 and $80 \%$ exposure among the negative bulk milk samples, was detected with 76.9 and $54.6 \%$ power, respectively (Sampsize software, http://sampsize.sourceforge.net/iface/s3.html).

\section{DISCUSSION}

Ours is the first extensive study describing the prevalence and distribution of CNS species in bulk milk of a large number of samples and dairy herds. The use of MSA as a (quasi-)selective medium along with the molecular speciation of all phenotypically different CNS isolates allowed us to precisely describe the species-specific prevalence and distribution of CNS in bulk milk over $1 \mathrm{yr}$ and to identify subgroup- and even species-specific herd-level risk factors, whereas previous studies identified herd-level risk factors for CNS as a group (Sampimon et al., 2009; Piepers et al., 2011). The current findings add to recent CNS research looking at the ecology and epidemiology (Bexiga et al., 2014; De Visscher et al., 2016a,b), the association with milk yield (Compton et al., 2007; Piepers et al., 2013), the effect on udder health (Supré et al., 2011; Fry et al., 2014), and the immune response following experimental challenge (Simojoki et al., 2011; Piccart et al., 2016).

Coagulase-negative staphylococci are prevalent in bulk milk in Flanders (De Visscher et al., 2013), though the species-specific prevalence and distribution greatly varied among herds. Staphylococcus aureus and the more relevant CNS species for udder health were recovered in almost equal numbers, though their presence was negatively associated and no seasonal effect was observed for $S$. aureus. The prevalence of $S$. aureus corresponds well with earlier reported results on the bulk milk prevalence of $S$. aureus (Olde Riekerink et al., 2006, 2010). However, bacteria in bulk milk do not 


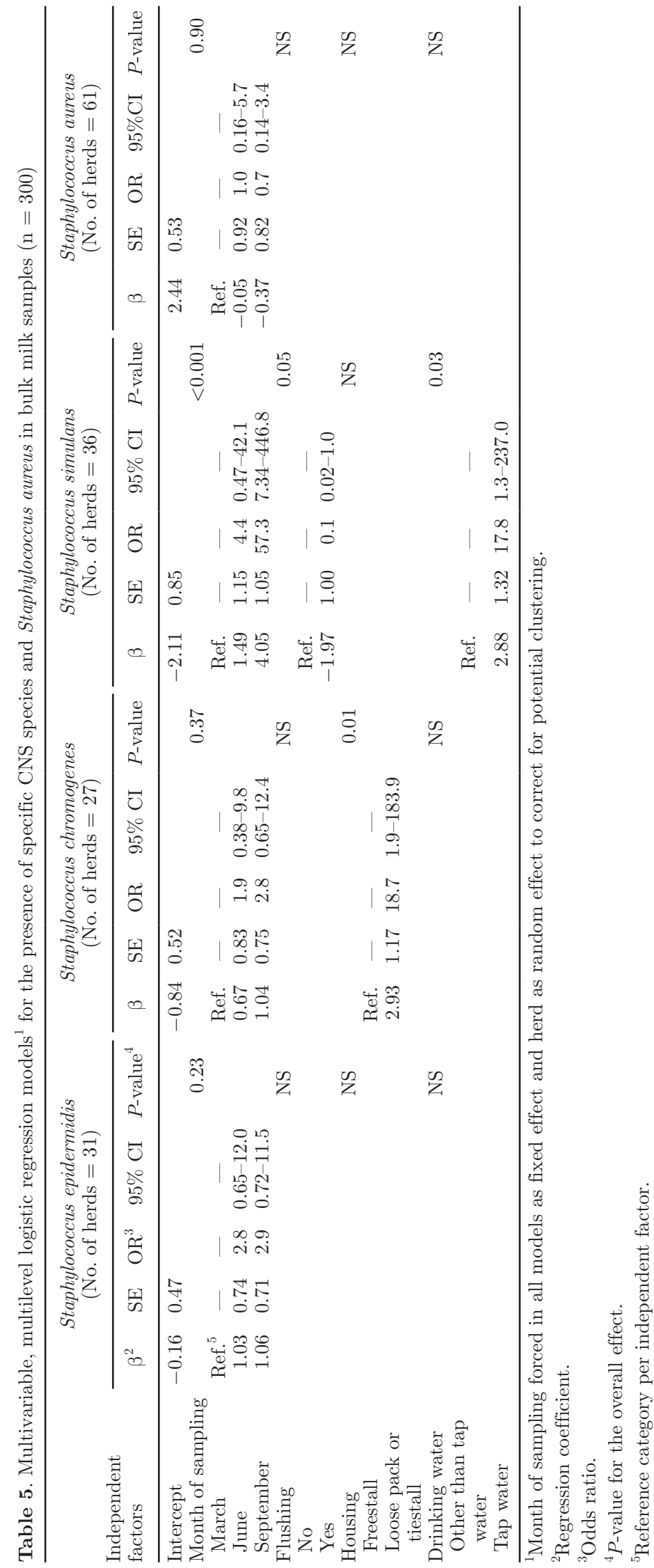




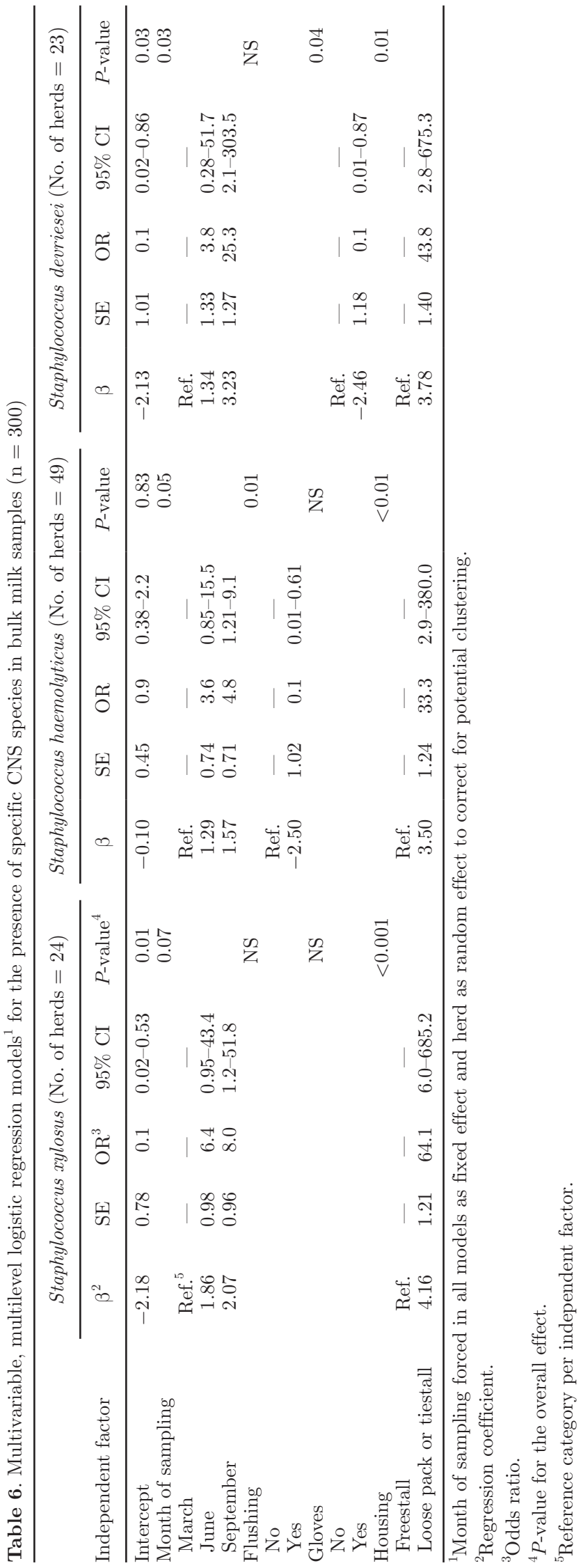

originate solely from infected quarters; environmental contamination or insufficient hygiene and poor preservation conditions can also cause positive bulk milk samples, potentially hampering the interpretation of the data (Elmoslemany et al., 2009a,b), which also applies for the current study. Although our study revealed the presence of the both so-called host-adapted (e.g., $S$. chromogenes) and environmental CNS species (e.g., $S$. equorum; Piessens et al., 2011; Vanderhaeghen et al., 2015) in bulk milk, studying the presence of CNS in bulk milk samples and the presence in quarter milk and environmental samples at the same time, relying on strain-typing, is necessary to determine the exact origin of the CNS in bulk milk.

A seasonal effect was observed, which is in contrast with earlier CNS group studies (Gillespie et al., 2012) and in line with the results from Østerås et al. (2006); differences among species should be further explored. Bad housing conditions and poor hygiene are important factors increasing the total bacterial count in bulk milk (Olde Riekerink et al., 2010). Housing of lactating animals most likely also plays an important role in our study, as the presence of only 3 species was not associated with this risk factor (i.e., S. cohnii, S. epidermidis, and $S$. simulans). The latter might either indicate the ubiquitous nature of those 3 species both in freestall and loose pack or tiestall barns (perhaps for $S$. cohnii) or suggest a more cow-dependent presence in bulk milk (true for the cow-adapted CNS S. epidermidis and $S$. simulans). Cleaning of the cubicles or loose pack was not associated with the presence of any CNS species in our study; however, bedding maintenance was not visually checked. Caution is thus needed in drawing conclusions.

Clipping of the udders, particularly in September, reduced the odds of having bulk milk positive for the more relevant CNS species (i.e., S. chromogenes, $S$. simulans, and S. xylosus; Supré et al., 2011; Fry et al., 2014; De Visscher et al., 2015). In herds where udders were clipped annually, udders were clipped $1(\mathrm{n}=37)$, $2(\mathrm{n}=12), 3(\mathrm{n}=5), 4(\mathrm{n}=3)$, or 6 times $(\mathrm{n}=$ 2 ) in 2013. In Flemish dairy herds, cows are kept in confined housing from around October to May. In this housed period, due to rather mild and humid climatic conditions, the udder and teats are exposed to high bacterial levels, increasing the risk for contamination, in particular for cows with long udder hairs. Previous work reported a negative association between clipping the udder before calving and CNS IMI at parturition (Piepers et al., 2011), which might indicate that the presence of $S$. chromogenes, S. simulans, and S. xylosus in bulk milk results at least partly from a transmission via the udder hairs. 
BOVINE COAGULASE-NEGATIVE STAPHYLOCOCCI IN BULK MILK

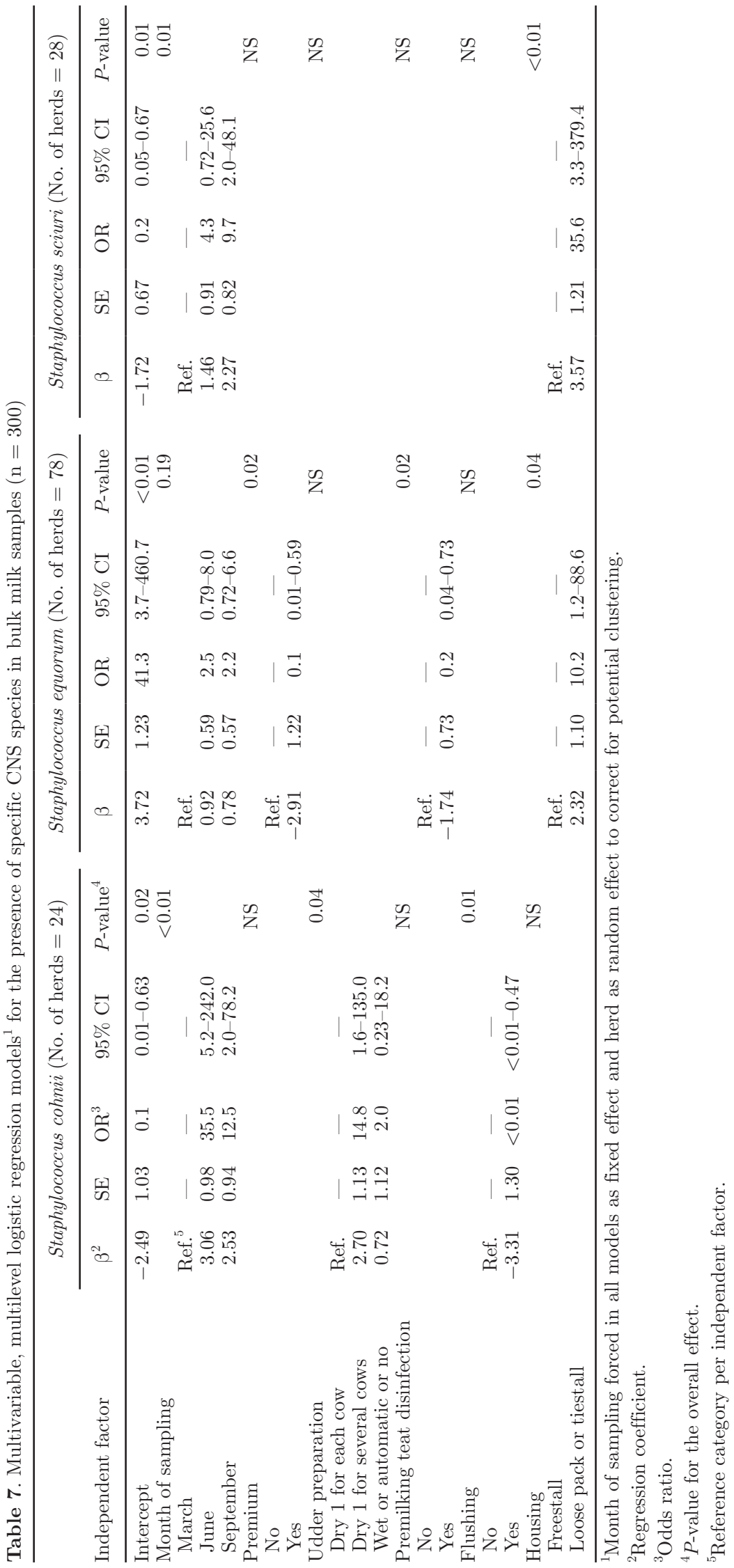


Nineteen herds did not receive their milk quality premium at least 1 time during the study period. The main reason for not receiving the milk quality premium in Flemish dairy herds is selling of milk with an elevated number of coliform bacteria $[>50 \mathrm{cfu} / \mathrm{mL}$; R. Passchyn (independent dairy consultant, Torhout, Belgium), S. Piepers, G. P. Keefe (University of Prince Edward Island, Charlottetown, Canada), and S. De Vliegher, unpublished data]. Therefore, it is not that surprising that especially the presence of $S$. equorum in the bulk milk samples was associated with not achieving the milk quality premium. Staphylococcus equorum has mainly been isolated from extramammary habitats, such as teat apices (Braem et al., 2013; De Visscher et al., 2014, 2016a), milking machine unit liners and milkers' skin and gloves (De Visscher et al., 2014), and the cow's environment (Piessens et al., 2011). In that respect, we hypothesize the S. equorum bulk milk contamination in the current study occurs from an environmental transfer (e.g., via the teat surface). This hypothesis is supported by the fact that the presence of $S$. equorum in the bulk milk was also negatively associated with premilking disinfection of the teats. Premilking teat disinfection lowered the likelihood of finding CNS in bulk milk (Jayarao et al., 2004), which can most likely be attributed to a more careful removal of environmental teat skin organisms before milking.

The use of a single towel for multiple cows enlarged the probability of isolating $S$. cohnii from the bulk milk. The latter practice increases both the risk of contamination of quarters and cows with environmental organisms and the risk of transmission of the more udderadapted pathogens to uninfected quarters and cows. Also, flushing of the milking cluster with hot water or steam after having milked a cow with (sub)clinical mastitis was negatively associated with the presence of $S$. cohnii in bulk milk. This association suggests the presence of $S$. cohnii in the teat liners, which is in accordance with previous work (De Visscher et al., 2014). The latter finding was explained by direct contact between teat skin and liners (De Visscher et al., 2014). Staphylococcus cohnii seems to have a similar ecological nature as compared with $S$. equorum, although in at least some studies $S$. cohnii has been more commonly isolated from bovine milk (Supré et al., 2011; Fry et al., 2014; De Visscher et al., 2016b). Bulk milk contamination with this species presumably occurred from environmental transmission via the teat surface and teat liners. However, the presence of $S$. cohnii in the bulk milk via teat liners contaminated with milk residues of S. cohnii-infected animals cannot be excluded. Hence, the need for further study exists, including work with quarter and bulk milk samples and strain typing.
Flushing with hot water or steam after having milked a cow with (sub)clinical mastitis was also negatively associated with the isolation of S. simulans and S. haemolyticus in the bulk milk. Both species have recently been assumed opportunistic in nature, as they have frequently been isolated from bovine IMI as well as from several extramammary habitats including the cow's environment (Piessens et al., 2011; Supré et al., 2011; Vanderhaeghen et al., 2015). The latter findings, along with the results from the current study, let us assume that the presence of S. simulans and S. haemolyticus in the bulk milk is the result of contamination from infected milk rather than from environmental transfer.

Wearing gloves decreased the odds of having $S$. devriesei-positive bulk milk. This is interesting, as in recent work $S$. devriesei could be hardly isolated from the milkers' hands or gloves (De Visscher et al., 2014). Staphylococcus devriesei has been mainly isolated from extramammary habitats, including teat apices from dry cows and end-term heifers and the cow's environment (Piessens et al., 2011; De Visscher et al., 2016a), and less from bovine IMI (Piessens et al., 2011; Supré et al., 2011; De Visscher et al., 2016b). Teat apices of lactating animals appear to be not (Taponen et al., 2008; De Visscher et al., 2014) or hardly colonized (Braem et al., 2013) with $S$. devriesei. The presence of this species in the bulk milk might be a result of environmental transfer via the teat surface along with contamination of the teats via the milkers' hands. However, more in-depth research concerning the ecology and epidemiological nature of $S$. devriesei is needed before better conclusions can be drawn.

Quarters infected with CNS are important contributors to the total number of somatic cells in well-managed herds with low bulk milk SCC (Piepers et al., 2009; Schukken et al., 2009; Sampimon et al., 2010). Likewise, mean bulk milk SCC was significantly associated with the mean CNS bulk milk count and isolation of $S$. aureus in bulk milk (Jayarao et al., 2004). In our study, however, no association between the bulk milk SCC and the presence of any of the CNS species or $S$. aureus was revealed. Although postmilking teat disinfection was found to decrease the total bacterial count in bulk milk (Jayarao et al., 2004) and is considered an effective control measure against both the host-adapted and environmental bacteria (Hogeveen et al., 2011), no species-specific associations were observed in our study. Still, the susceptibility of at least some CNS species to teat disinfectants has been questioned lately (Piessens et al., 2012; Tremblay et al., 2014).

Interestingly, participation in a monthly veterinary udder health program was positively associated with the presence of the CNS species previously reported 
causing an elevated quarter SCC (i.e., S. chromogenes, S. simulans, and S. xylosus). We suspect reverse causation, but the true nature of this association remains unknown. Because the more relevant CNS (i.e., $S$. chromogenes, S. simulans, and S. xylosus) have already been associated with an increased quarter SCC and have been shown to cause persistent IMI (Supré et al., 2011; Fry et al., 2014), we hypothesize that herds suffering from a high proportion of cows with an elevated SCC might have decided to monitor their udder health more closely with their veterinarian. An explanation for the association of drinking water with the isolation of S. simulans from bulk milk is also difficult. Sampimon et al. (2009) observed a negative association between drinking water and the presence of CNS in quarter milk samples. The positive association in the current study might be also attributed to a cause-effect reversal.

\section{CONCLUSIONS}

Bulk milk yields a wide range of different CNS species. Both so-called host-adapted as well as environmental CNS species are present. Several herd-level risk factors were associated with the presence of subgroups of as well as specific CNS species. Coagulase-negative staphylococci in bulk milk might originate from the environment for some species (we hypothesize this is true for S. equorum or S. cohnii, for example), or from within the udder (e.g., S. simulans). Studies collecting bulk and quarter milk samples at the same time, along with environmental samples, are needed to determine the exact origin of the different (subgroups of) CNS species present in bulk milk using strain-typing techniques.

\section{ACKNOWLEDGMENTS}

This study was funded by the Agency for Innovation by Science and Technology, Flanders (IWT-Vlaanderen, Brussels, Belgium; grant no. 111588). The authors want to thank Lars Hulpio (Department of Reproduction, Obstetrics, and Herd Health, Faculty of Veterinary Medicine, Ghent University, Merelbeke, Belgium) for his technical assistance.

\section{REFERENCES}

Bertelloni, F., F. Fratini, V. V. Ebani, A. Galiero, B. Turchi, and D. Cerri. 2015. Detection of genes encoding for enterotoxines, TSST1 , and biofilm production in coagulase-negative staphylococci from bovine bulk tank milk. Dairy Sci. Technol. 95:341-352.

Bexiga, R., M. G. Rato, A. Lemsaddek, T. Semedo-Lemsaddek, C. Carneiro, H. Pareira, D. J. Mellor, K. A. Ellis, and C. L. Vilela. 2014. Dynamics of bovine intramammary infections due to coagulase-negative staphylococci on four farms. J. Dairy Res. 81:208214.
Braem, G., S. De Vliegher, B. Verbist, V. Piessens, E. Van Coillie, L. De Vuyst, and F. Leroy. 2013. Unraveling the microbiota of teat apices of clinically healthy lactating dairy cows, with special emphasis on coagulase-negative staphylococci. J. Dairy Sci. 96:1499-1510

Compton, C. W. R., C. Heuer, K. Parker, and S. McDougall. 2007. Epidemiology of mastitis in pasture-grazed peripartum dairy heifers and its effects on productivity. J. Dairy Sci. 90:4157-4170.

De Visscher, A., F. Haesebrouck, S. Piepers, W. Vanderhaeghen, K. Supré, F. Leroy, E. Van Coillie, and S. De Vliegher. 2013. Assessment of the suitability of mannitol salt agar for growing bovineassociated coagulase-negative staphylococci and its use under field conditions. Res. Vet. Sci. 95:347-351.

De Visscher, A., S. Piepers, F. Haesebrouck, and S. De Vliegher. 2016a. Teat apex colonization with coagulase-negative Staphylococcus species before parturition: distribution and species-specific risk factors. J. Dairy Sci. 99:1427-1439.

De Visscher, A., S. Piepers, F. Haesebrouck, and S. De Vliegher. 2016b. Intramammary infection with coagulase-negative staphylococci at parturition: species-specific prevalence, risk factors, and impact on udder health. J. Dairy Sci. 99:6457-6469. https://doi. org/10.3168/jds.2015-10458.

De Visscher, A., S. Piepers, K. Supré, F. Haesebrouck, and S. De Vliegher. 2015. Short communication: Species group-specific predictors at the cow and quarter level for intramammary infection with coagulase-negative staphylococci in dairy cattle throughout lactation. J. Dairy Sci. 98:5448-5453.

De Visscher, A., K. Supré, F. Haesebrouck, R. N. Zadoks, V. Piessens, E. Van Coillie, S. Piepers, and S. De Vliegher. 2014. Further evidence for the existence of environmental and host-associated species of coagulase-negative staphylococci in dairy cattle. Vet. Microbiol. 172:466-474.

Elmoslemany, A. M., G. P. Keefe, I. R. Dohoo, and T. R. Dingwell. 2009a. Microbiological quality of bulk tank raw milk in Prince Edward Island dairy herds. J. Dairy Sci. 92:4239-4248.

Elmoslemany, A. M., G. P. Keefe, I. R. Dohoo, and B. M. Jayarao. 2009b. Risk factors for bacteriological quality of bulk tank milk in Prince Edward Island dairy herds. Part 2: Bacteria count-specific risk factors. J. Dairy Sci. 92:2644-2652.

Fox, L. K. 2009. Prevalence, incidence and risk factors for heifer mastitis. Vet. Microbiol. 134:82-88.

Fry, P. R., J. R. Middleton, S. Dufour, J. Perry, D. Scholl, and I. Dohoo. 2014. Association of coagulase-negative staphylococcal species, mammary quarter milk somatic cell count, and persistence of intramammary infection in dairy cattle. J. Dairy Sci. $97: 4876-4885$

Gillespie, B. E., M. J. Lewis, S. Boonyayatra, M. L. Maxwell, A. Saxton, S. P. Oliver, and R. A. Almeida. 2012. Short communication: Evaluation of bulk tank milk microbiological quality of nine dairy farms in Tennessee. J. Dairy Sci. 95:4275-4279.

Goldstein, H., R. W. Browne, and J. Rasbash. 2002. Partitioning variation in multilevel models. Underst. Stat. 4:223-231.

Hogeveen, H., K. Huijps, and T. J. G. M. Lam. 2011. Economic aspects of mastitis: New developments. N. Z. Vet. J. 59:16-23.

Jayarao, B. M., S. R. Pillai, A. A. Sawant, D. R. Wolfgang, and N. V. Hegde. 2004. Guidelines for monitoring bulk milk somatic cell count and bacterial counts. J. Dairy Sci. 87:3561-3573.

Noordhuizen, J. P. T. M., K. Frankena, M. V. Thursfield, and E. A. M. Graat. 2001. Application of Quantitative Methods in Veterinary Epidemiology. Wageningen Pers, Wageningen, the Netherlands.

Olde Riekerink, R. G. M., H. W. Barkema, D. T. Scholl, D. E. Poole, and D. F. Kelton. 2010. Management practices associated with the bulk-milk prevalence of Staphylococcus aureus in Canadian dairy farms. Prev. Vet. Med. 97:20-28.

Olde Riekerink, R. G. M., H. W. Barkema, S. Veenstra, D. E. Poole, R. T. Dingwell, and G. P. Keefe. 2006. Prevalence of contagious mastitis pathogens in bulk tank milk in Prince Edward Island. Can. Vet. J. 47:567-572.

Østerås, O., L. Sølverød, and O. Reksen. 2006. Milk culture results in a large Norwegian survey. Effects of season, parity, days in milk, resistance, and clustering. J. Dairy Sci. 89:1010-1023. 
Park, J. Y., L. K. Fox, K. S. Seo, M. A. McGuire, Y. H. Park, F. R. Rurangirwa, W. M. Sischo, and G. A. Bohach. 2011. Comparison of phenotypic and genotypic methods for the species identification of coagulase-negative staphylococcal isolates from bovine intramammary infections. Vet. Microbiol. 147:142-148.

Piccart, K., J. Verbeke, A. De Visscher, S. Piepers, F. Haesebrouck, and S. De Vliegher. 2016. Local host response following an intramammary challenge with Staphylococcus fleurettii and different strains of Staphylococcus chromogenes in dairy heifers. Vet. Res. 47:56.

Piepers, S., L. De Meulemeester, A. de Kruif, G. Opsomer, H. W. Barkema, and S. De Vliegher. 2007. Prevalence and distribution of mastitis pathogens in subclinically infected dairy cows in Flanders, Belgium. J. Dairy Res. 74:478-483.

Piepers, S., S. De Vliegher, A. de Kruif, G. Opsomer, and H. W Barkema. 2009. Impact of intramammary infections in dairy heifers on future udder health, milk production, and culling. Vet. Microbiol. 134:113-120.

Piepers, S., K. Peeters, G. Opsomer, H. W. Barkema, K. Frankena, and S. De Vliegher. 2011. Pathogen group specific risk factors at herd, heifer and quarter levels for intramammary infections in early lactating dairy heifers. Prev. Vet. Med. 99:91-101.

Piepers, S., Y. H. Schukken, P. Passchyn, and S. De Vliegher. 2013 The effect of intramammary with coagulase-negative staphylococci in early lactating heifers on milk yield throughout first lactation revisited. J. Dairy Sci. 96:5095-5105.

Piessens, V., S. De Vliegher, B. Verbist, G. Braem, A. Van Nuffel, L. De Vuyst, M. Heyndirckx, and E. Van Coillie. 2012. Characterization of coagulase-negative Staphylococcus species from cows' milk and environment based on bap, icaA, and mecA genes and phenotypic susceptibility to antimicrobials and teat dips. J. Dairy Sci. 95:7027-7038.

Piessens, V., E. Van Coillie, B. Verbist, K. Supré, G. Braem, A. Van Nuffel, L. De Vuyst, M. Heyndrickx, and S. De Vliegher. 2011. Distribution of coagulase-negative Staphylococcus species from dairy cows' milk and environment differs between herds. J. Dairy Sci. 94:2933-2944.

Reyher, K. K., S. Dufour, H. W. Barkema, L. Des Côteaux, T. J. DeVries, I. R. Dohoo, G. P. Keefe, J.-P. Roy, and D. T. Scholl. 2011. The national cohort of dairy farms. A data collection platform for mastitis research in Canada. J. Dairy Sci. 94:1616-1626.

Sampimon, O., B. H. P. van den Borne, I. Santman-Berends, H. W. Barkema, and T. Lam. 2010. Effect of coagulase-negative staphylococci on somatic cell count in Dutch dairy herds. J. Dairy Res. $77: 318-324$.

Sampimon, O. C., H. W. Barkema, I. M. G. A. Berends, J. Sol, and T. J. G. M. Lam. 2009. Prevalence and herd-level risk factors for intramammary infection with coagulase-negative staphylococci in Dutch dairy herds. Vet. Microbiol. 134:37-44.

Santos, O. C. S., E. M. Barros, M. A. V. P. Brito, M. C. F. Bastos, K. R. N. Santos, and M. Giambiagi-deMarval. 2008. Identification of coagulase-negative staphylococci from bovine mastitis using RFLP-PCR of the groEL gene. Vet. Microbiol. 130:134-140.

Schukken, Y. H., R. N. González, L. L. Tikofsky, H. F. Schulte, C. G. Santisteban, F. L. Welcome, G. J. Bennett, M. J. Zurakowski, and R. N. Zadoks. 2009. CNS mastitis: Nothing to worry about? Vet. Microbiol. 134:9-14.

Simojoki, H., T. Salomaki, S. Taponen, A. Iivanainen, and S. Pyörälä. 2011. Innate immune response in experimentally induced bovine intramammary infection with Staphylococcus simulans and S. epidermidis. Vet. Res. 42:49.

Supré, K., S. De Vliegher, O. C. Sampimon, R. N. Zadoks, M. Vaneechoutte, M. Baele, E. De Graef, S. Piepers, and F. Haesebrouck. 2009. Technical note: Use of transfer RNA-intergenic spacer PCR combined with capillary electrophoresis to identify coagulase-negative Staphylococcus species originating from bovine milk and teat apices. J. Dairy Sci. 92:3204-3210.

Supré, K., F. Haesebrouck, R. N. Zadoks, M. Vaneechoutte, S. Piepers, and S. De Vliegher. 2011. Some coagulase-negative Staphylococcus species affect udder health more than others. J. Dairy Sci. 94:2329-2340.

Sztachańska, M., W. Barański, T. Janowski, P. Pogorzelska, and S. Zduńczy. 2016. Prevalence and etiological agents of subclinical mastitis at the end of lactation in nine dairy herds in northeast Poland. Pol. J. Vet. Sci. 19:119-124.

Taponen, S., J. Björkroth, and S. Pyörälä. 2008. Coagulase-negative staphylococci isolated from bovine extramammary sites and intramammary infections in a single dairy herd. J. Dairy Res. 75:422429.

Tremblay, Y. D. N., V. Caron, A. Blondeau, S. Messier, and M. Jacques. 2014. Biofilm formation by coagulase-negative staphylococci: impact on the efficacy of antimicrobials and disinfectants commonly used on dairy farms. Vet. Microbiol. 172:511-518.

Vanderhaeghen, W., S. Piepers, F. Leroy, E. Van Coillie, F. Haesebrouck, and S. De Vliegher. 2015. Identification, typing, ecology and epidemiology of coagulase-negative staphylococci associated with ruminants. Vet. J. 203:44-51.

Waller, K. P., A. Aspán, A. Nyman, Y. Persson, and U. Grönlund Andersson. 2011. CNS species and antimicrobial resistance in clinical and subclinical bovine mastitis. Vet. Microbiol. 152:112-116.

Zadoks, R. N., H. G. Allore, H. W. Barkema, O. C. Sampimon, G. J. Wellenberg, Y. T. Gröhn, and Y. H. Schukken. 2001. Cow- and quarter-level risk factors for Streptococcus uberis and Staphylococcus aureus mastitis. J. Dairy Sci. 84:2649-2663. 